\title{
Deletion of Annexin 2 Light Chain p11 in Nociceptors Causes Deficits in Somatosensory Coding and Pain Behavior
}

\author{
Thomas Foulkes, ${ }^{1}$ Mohammed A. Nassar, ${ }^{1}$ Tim Lane, ${ }^{1}$ Elizabeth A. Matthews, ${ }^{2}$ Mark D. Baker, ${ }^{1}$ Volker Gerke, ${ }^{3}$ \\ Kenji Okuse, ${ }^{4}$ Anthony H. Dickenson, ${ }^{2}$ and John N. Wood ${ }^{1}$ \\ ${ }^{1}$ Molecular Nociception Group, Department of Biology, and 2Department of Pharmacology, University College London, London WC1E 6BT, United \\ Kingdom, ${ }^{3}$ Institute of Medical Biochemistry, Center for Molecular Biology of Inflammation, University of Muenster, 48149 Muenster, Germany, and \\ ${ }^{4}$ Division of Cell and Molecular Biology, Imperial College, London SW7 2AZ, United Kingdom
}

The S100 family protein p11 (S100A10, annexin 2 light chain) is involved in the trafficking of the voltage-gated sodium channel $\mathrm{Na}_{\mathrm{V}} 1.8$, TWIK-related acid-sensitive $\mathrm{K}^{+}$channel (TASK-1), the ligand-gated ion channels acid-sensing ion channel 1a (ASIC1a) and transient receptor potential vanilloid 5/6 (TRPV5/V6), as well as 5-hydroxytryptamine receptor 1B (5-HT $1 \mathrm{~B}$ ), a G-protein-coupled receptor. To evaluate the role of $\mathrm{p} 11$ in peripheral pain pathways, we generated a loxP-flanked (floxed) p11 mouse and used the Cre-loxP recombinase system to delete p11 exclusively from nociceptive primary sensory neurons in mice. p11-null neurons showed deficits in the expression of $\mathrm{Na}_{\mathrm{V}} 1.8$, but not of annexin 2. Damage-sensing primary neurons from these animals show a reduced tetrodotoxin-resistant sodium current density, consistent with a loss of membrane-associated $\mathrm{Na}_{\mathrm{V}} 1.8$. Noxious coding in wide-dynamic-range neurons in the dorsal horn was markedly compromised. Acute pain behavior was attenuated in certain models, but no deficits in inflammatory pain were observed. A significant deficit in neuropathic pain behavior was also apparent in the conditional-null mice. These results confirm an important role for $\mathrm{p} 11$ in nociceptor function.

Key words: conditional knock-out; Cre-loxP; $\mathrm{Na}_{\mathrm{v}} 1.8$; neuropathic pain; p11; pain behavior

\section{Introduction}

The EF hand superfamily protein p11 (S100A10, annexin 2 light chain) exists as a heterotetramer with the $\mathrm{Ca}^{2+}$ - and phospholipid-binding protein annexin 2 . It is characterized by two consecutive EF hands connected by a flexible linker region and flanked by $\mathrm{N}$ - and C-terminal extensions. In contrast to other S100 proteins, $\mathrm{p} 11$ is $\mathrm{Ca}^{2+}$-independent because of a mutation in its two EF hand loops. This results in a permanently active conformation with respect to annexin binding (for review, see Gerke and Moss, 2002).

p11 plays an important role in the trafficking of transmembrane proteins. It binds directly to several ion channels, regulating the functional expression of the voltage-gated sodium channel $\mathrm{Na}_{\mathrm{V}} 1.8$ (Okuse et al., 2002), acid-sensing ion channel 1a (ASIC1a) (Donier et al., 2005), transient receptor potential vanilloid 5/6 (TRPV5/V6) (van de Graaf et al., 2003), TWIK-related (tandem of P-domains in a weakly inward rectifying $\mathrm{K}^{+}$channel) acid-sensitive $\mathrm{K}^{+}$channel-1 (TASK-1) (Girard et al., 2002; Renigunta et al., 2006), and the G-protein-coupled receptor

\footnotetext{
Received May 10, 2006; revised Aug. 18, 2006; accepted Aug. 21, 2006.

T.F. was the recipient of a Biotechnology and Biological Sciences Research Council (BBSRC) PhD studentship, partly funded by Vernalis Pharmaceuticals. We thank the BBSRC, Vernalis, the Medical Research Council, and the Wellcome Trust for their support. We thank Bjarke Abrahamsen for technical assistance and Lodewijk Dekker for helpful comments. We also thank the University of Michigan for help with the production of chimeric floxed p11 mice.

Correspondence should be addressed to John N. Wood, Molecular Nociception Group, Department of Biology, University College London, Gower Street, London WC1E 6BT, UK. E-mail: j.wood@ucl.ac.uk.

D0I:10.1523/JNEUROSCI.1997-06.2006

Copyright $\odot 2006$ Society for Neuroscience $\quad$ 0270-6474/06/2610499-09\$15.00/0
}

5-hydroxytryptamine receptor $1 \mathrm{~B}\left(5-\mathrm{HT}_{1 \mathrm{~B}}\right)$ (Svenningsson et al., 2006). Different channels appear to bind to distinct sites on $\mathrm{p} 11$ (although not all have been mapped), suggesting the possibility of simultaneous trafficking of several proteins by 11 .

At least two channels regulated by $\mathrm{p} 11, \mathrm{Na}_{\mathrm{V}} 1.8$ and ASIC1a, are involved in nociception (detection of noxious stimuli). $\mathrm{Na}_{V} 1.8$ has been found to contribute substantially to action potential electrogenesis in C-type dorsal root ganglia (DRG) neurons (Renganathan et al., 2001). Gene deletion studies in the mouse demonstrated a specialized function for $\mathrm{Na}_{\mathrm{V}} 1.8$ [sensory neuron-specific (SNS), SCN10A] in pain pathways (Akopian et al., 1999), with null mutants showing deficits in noxious mechanosensation and inflammatory hyperalgesia. ASIC1a is expressed in small-diameter nociceptive neurons of the DRG (Voilley et al., 2001), suggesting a role in nociception. It also is involved in synaptic plasticity and fear conditioning in the brain (Wemmie et al., 2002, 2003) and may be important in stroke (Yermolaieva et al., 2004). TASK-1 is a strongly pH-sensitive $\mathrm{K}^{+}$"leak" channel that is expressed in brain and contributes to resting membrane potentials (Duprat et al., 1997). The 5- $\mathrm{HT}_{1 \mathrm{~B}}$ receptor is expressed in DRG neurons (Nicholson et al., 2003), although the significance of this has yet to be examined.

We hypothesize that p11 may function as a nociceptive scaffolding protein in DRG neurons, bringing together proteins required for nociception at the plasma membrane. Interestingly, p11 has been shown to be upregulated by inflammatory mediators, including nerve growth factor (NGF) (Masiakowski and Shooter, 1988) and nitric oxide (Pawliczak et al., 2001). There are 
currently no small-molecule inhibitors of p11 function. p11 and/or annexin 2 are involved in many non-nociceptive processes, including fibrin homeostasis and angiogenesis (Ling et al., 2004), and depression (Svenningsson et al., 2006), suggesting that global p11 deletion would give a complex and potentially confounded pain phenotype. We therefore investigated the role of p11 in nociception by generating floxed p11 mice. We used the Cre-loxP recombinase system to delete p11 only in nociceptive neurons present in DRG by crossing the floxed p11 mouse line with the nociceptor-specific $\mathrm{Na}_{\mathrm{V}} 1.8$ Cre line (Stirling et al., 2005). We present an analysis of nociception and pain behavior in these DRG-specific p11-null mice.

\section{Materials and Methods}

Gene targeting: generation of conditional S100A10-null mice. Exon 2 of p11 was flanked by loxP sites. Exon 2 is the first translated region of the S100A 10 gene. A 200 base pair probe for $\mathrm{p} 11$ was prepared by PCR, using 129-derived embryonic stem cell DNA as a template with primers (gccaactggagcactggtaccccc and ggatacaaacaatataaaactcagaagc). This probe was used to identify genomic clones from an RCPI-22 129S6/SvEvTac mouse bacterial artificial chromosome (BAC) library. The targeting vector was derived from two overlapping BamHI and ApaI genomic subclones that contained both exons 2 and 3 of p11. The $5^{\prime}$ arm is the $4412 \mathrm{bp}$ $B a m \mathrm{HI}-\mathrm{XbaI}$ fragment upstream of exon 2. The loxP-flanked (floxed) exon 2 was obtained as a $990 \mathrm{bp} \mathrm{XbaI-ApaI} \mathrm{fragment.} \mathrm{The} 3^{\prime}$ arm is the 6422 ApaI-XmaI fragment downstream of exon 2. The three genomic fragments were inserted into a plasmid containing two loxP sites and an FLP recombination target-flanked [FRT-flanked (flrted)] neo cassette (Nassar et al., 2004).

The complete targeting vector was linearized and electroporated into 129-derived embryonic stem cells and screened as described by Nassar et al. (2004), using 5' and 3' external probes for Southern blot. Two correctly targeted clones were injected into $\mathrm{C} 57 \mathrm{BL} / 6 \mathrm{~J}$ blastocysts to generate chimeras. Electroporation and injection were performed by the University of Michigan (Ann Arbor, MI). These chimeras were crossed to C57BL/6 animals. This was followed by a cross to FLPe deleter mice (Farley et al., 2000) to excise the positive selection marker. Correct targeting was confirmed by Southern blot (digestion by EcoRI or BamHI). Finally, these mice were crossed to mice expressing Cre under the control of the $\mathrm{Na}_{\mathrm{V}} 1.8$ promoter (Stirling et al., 2005). These mice express Cre in small-diameter $(<25 \mu \mathrm{m})$ neurons arising from the DRG, of which $>85 \%$ are nociceptors (Akopian et al., 1996; Djouhri et al., 2003). Further crosses between floxed mice and floxed mice heterozygous for $\mathrm{Na}_{\mathrm{V}} 1.8$ Cre generated conditional-null mutants and floxed littermate controls for analysis. This ensured an identical genetic background between p11 conditional-null and control animals, which had been backcrossed to F5 on a C57BL/6 background. Genotyping for floxed versus wild-type mice was performed by using the primers p11 Sequence 1 (ccttctctgctgaacttgataatgaa) and p11 Sequence 4 (tcttggcacagaacatgtaat$\mathrm{tcttt}$ ) whereas the presence of the gene coding for Cre was detected by using the primers Cre 2s (ctgcattaccggtcgatgcaacga) and Cre 5a (aatgttgctggatagttttactgcc). Additionally, the floxed p11 mice were crossed to a "global" Cre-expressing strain (Schwenk et al., 1995) to produce a global p11-null animal for Western blotting experiments. Protein extraction from conditional-null animals would result in a mixture of protein from p11-containing and p11-null cells, obscuring any changes in protein levels that p11 deletion may cause.

Deletion of p11 from nociceptive DRG neurons was confirmed by PCR and reverse transcription-PCR (RT-PCR) (primers tgtgcccagctcttccaagg and acaagaagcagtggggcagat). PCR and Southern blot were performed according to standard procedures (Sambrook et al., 1989). RNA isolation was performed with Trizol reagent (Invitrogen, Paisley, UK), according to the manufacturer's protocol. The RT reaction also was performed according to an Invitrogen protocol, using an oligo-dT primer to allow mRNA-specific RT.

Western blot. Membrane proteins were isolated from freshly excised DRG taken from floxed p11 and p11 global-null animals (global-null to ensure all protein came from p11-null cells). All steps were performed at $4^{\circ} \mathrm{C}$. DRG were homogenized in $10 \mathrm{vol}$ homogenization buffer $(0.32 \mathrm{M}$ sucrose, 10 mM HEPES, pH 7.4, and 2 mM EDTA plus protease inhibitors leupeptin, pepstatin, phenylmethylsulfonyl fluoride, benzamidine, aprotinin), using 15 strokes of a glass-Teflon homogenizer. Centrifugation for $15 \mathrm{~min}$ at $1000 \times g$ removed the nuclear fraction. Then the supernatant was centrifuged at $200,000 \times g$ for $15 \mathrm{~min}$, washed in homogenization buffer, and resuspended in HEPES-lysis buffer (50 mM HEPES, $\mathrm{pH}$ 7.4, 2 mM EDTA, protease inhibitors). SDS (4\%) and Triton X-100 (2\%) were included to allow for solubility of $\mathrm{Na}_{\mathrm{V}} 1.8$ (Djouhri et al., 2003). Protein concentrations (floxed p11 and p11-null) were matched using the bicinchoninic acid (BCA) assay (Smith et al., 1985); then samples of 20 or $40 \mu \mathrm{g}$ (or $400 \mu \mathrm{g}$ for anti-Na 1.8 total cell lysate) were subjected to SDS-PAGE $(8-12 \%$ gel). Proteins were transferred to a nitrocellulose membrane (Hybond, Amersham Biosciences, Buckinghamshire, UK) in transfer buffer (25 mm Tris-HCl, pH 8.3, 192 mm glycine, 0.1\% SDS, 20\% methanol) for $1 \mathrm{~h}$ at $100 \mathrm{~V}$. The membrane was blocked with $5 \%$ nonfat milk in TBS-Tween $(0.1 \%)$ for $1 \mathrm{~h}$ at room temperature and then incubated with primary antibody [anti-p11 (R \& D Systems, Minneapolis, $\mathrm{MN}$ ), anti-annexin 2 (a kind gift from Professor Volker Gerke, University of Muenster, Muenster, Germany), anti-ASIC1 (Alomone Labs, Buckinghamshire, UK), anti-5- $\mathrm{HT}_{1 \mathrm{~B}}$ (Abcam, Cambridge, UK), anti$\mathrm{Na}_{\mathrm{V}} 1.8$ ] diluted 1:1000-1:5000 in blocking buffer overnight at $4^{\circ} \mathrm{C}$. The membrane was washed three times with TBS-Tween, and secondary antibody [horseradish peroxidase-conjugated goat anti-mouse or antirabbit IgG (Jackson ImmunoResearch, West Grove, PA)] was applied at 1:1000 in TBS-Tween for $2 \mathrm{~h}$ at room temperature. Detection was performed by ECL detection reagent (Amersham Biosciences) and exposed to BioMax film (Kodak, Harrow, UK). After detection the membranes were stripped of antibody by using high concentrations of glycine, SDS, and $\beta$-mercaptoethanol at $50^{\circ} \mathrm{C}$. After a reprobing with a secondary antibody to confirm removal of the primary antibody, the membranes were reprobed with anti- $\mathrm{Na}^{+} / \mathrm{K}^{+}$-ATPase (Santa Cruz Biotechnology, Santa Cruz, CA) and anti-rabbit secondary antibody (as before). This was used as a protein loading control.

Immunohistochemistry. DRG were excised from humanely killed mice ( 11 conditional-null or floxed littermate control) and frozen in OCT. Sections were processed and stained as described by Stirling et al. (2005).

Immunocytochemistry. DRG neurons were excised from p11 conditional-null and floxed littermate control mice and were cultured on poly-L-lysine and laminin-coated glass coverslips for $24-48 \mathrm{~h}$. Cells were fixed using $4 \%$ paraformaldehyde for $5 \mathrm{~min}$ at room temperature (or for anti-p11, methanol for $10 \mathrm{~min}$ at $-20^{\circ} \mathrm{C}$ ), washed (three times for $5 \mathrm{~min}$ ) in PBS, and then blocked and permeabilized in PBS containing $0.1 \%$ Triton X-100 and 10\% goat serum for $20 \mathrm{~min}$ at room temperature. Cells were incubated with primary antibody diluted in blocking solution [antip11, 1:2-400; (a kind gift from Professor Volker Gerke); other antibodies as Western blot; anti-annexin 2, 1:400; anti-p11, 1:200] for $2 \mathrm{~h}$, washed, and then exposed to secondary antibody (Alexa 488 or 595) diluted 1:800 for $1 \mathrm{~h}$. After a final wash the coverslips were mounted on slides with Citifluor (Citifluor Products, Leicester, UK) to prevent bleaching. Images were obtained using a Zeiss (Oberkochen, Germany) conventional fluorescent or confocal microscope.

Whole-cell patch-clamp recordings. DRG neuron cultures were prepared from humanely killed p11 conditional-null or floxed littermate control mice aged $4-8$ weeks, as described previously (Stirling et al., 2005). Neurons were maintained in culture in the presence of NGF $(0.25$ $\mu \mathrm{g} / \mathrm{ml}$ ) for a maximum of $48 \mathrm{~h}$. Whole-cell patch clamp was performed in the absence of tetrodotoxin (TTX), followed by the addition of $250 \mathrm{nM}$ TTX to the bathing solution by acute local superfusion.

Voltage-clamp recordings were made from single DRG neurons of $\leq 25 \mu \mathrm{m}$ in diameter, using an Axopatch 200B amplifier controlled by pClamp 9.0 software (both from Molecular Devices, Union City, CA). Neurons were voltage-clamped at $-80 \mathrm{mV}$, except when a noticeable $\mathrm{Na}_{\mathrm{V}}$ 1.9-mediated current was observed, where the cells were held at -60 $\mathrm{mV}$ to inactivate this channel. Series resistance was compensated for at $70-80 \%$, using a feedback lag of $12 \mu$ s. Currents were elicited by incremental $(+10 \mathrm{mV})$ depolarizing steps (50 ms duration), preceded by a hyperpolarizing pulse to $-100 \mathrm{mV}$ to remove any inactivation. Averages of three sweeps were taken to form the current records, which were 
filtered at $5 \mathrm{kHz}$. TTX-sensitive currents were obtained by digital subtraction of the TTX-resistant current from total current. Current density estimates were made from stable, maximal current amplitudes. All currents included in the analysis appeared normal, corresponding to TTXsensitive or TTX-resistant $\mathrm{Na}^{+}$channels. Current densities were compared using a Mann-Whitney rank sum test.

In vivo recordings from dorsal horn neurons. Measurements of electrical inputs into wide-dynamic-range (WDR) neurons in the spinal cord were performed as described previously (Matthews et al., 2006) in urethaneanesthetized mice. Single neuron extracellular recordings were made after electrical, mechanical, or thermal stimulation of varying magnitude. $\mathrm{A}$ - and C-fiber-mediated responses were distinguished by latency relative to initial stimulus. Neuronal responses occurring after the C-fiber latency band of the neuron $(250-800 \mathrm{~ms})$ were classed as postdischarge, a result of repeated stimulation leading to wind-up neuronal hyperexcitability. The "input" (nonpotentiated response) and the "wind-up" (potentiated response, evident by increased neuronal excitability to repeated stimulation) were calculated as follows: Input $=$ action potentials $(50-800 \mathrm{~ms})$ evoked by first pulse at $3 \times \mathrm{C}$-fiber threshold $\times$ total number of pulses (16). Wind-up = total action potentials $(90-800 \mathrm{~ms})$ after 16 train stimulus at $3 \times$ C-fiber threshold) - Input. Data are presented as the mean \pm SEM. Two-factor ANOVA with replication was used for statistical analysis, and the level of significance was taken to be $p<0.05$.

Behavioral analysis. All tests were approved under the United Kingdom Home Office Animals (Scientific Procedures) Act, 1986, and were performed on animals aged between 8 and 16 weeks. Behavioral analysis was performed as described by Stirling et al. (2005) (rotarod, Hargreaves' apparatus, hotplate, von Frey, Randall-Selitto, and sciatic nerve injury) and by Akopian et al. (1999) (carrageenan).

Formalin test. The formalin model was performed by intraplantar injection (subcutaneously) of $20 \mu \mathrm{l}$ of a $5 \%$ formalin solution into the left hindpaw after a $15 \mathrm{~min}$ acclimatization to individual observation cages. Time spent engaged in nociceptive behavior (biting or licking the affected region) was recorded in 5 min sections over $1 \mathrm{~h}$ immediately after injection. Phase 1 was defined as $0-10 \mathrm{~min}$, whereas subsequent behavior was defined as Phase 2. Results were compared by using an unpaired two-tailed Student's $t$ test.

Nerve growth factor. After a baseline Hargreaves' test, 50 ng of human recombinant NGF was delivered to the left hindpaw by intraplantar injection. Subsequent Hargreaves' tests were performed at $30 \mathrm{~min}$ after injection and then every hour for $6 \mathrm{~h}$. Results were expressed as a proportion of baseline for each animal.

All results are expressed as mean \pm SEM. The level of significance was set at $p<0.05$.

\section{Results}

\section{p11 is deleted from nociceptive neurons, but not from}

\section{other tissues}

We generated a floxed p11 mouse line and crossed it with a $\mathrm{Na}_{\mathrm{V}} 1.8$ Cre mouse line to effect gene deletion in nociceptors. The construct used to flox exon 2 of p11 and the targeting event are shown in Figure 1a. Southern blotting (Fig. 1b) and PCR (data not shown) were used to confirm the correct targeting of the p11 locus. In Southern blots BamHI (bands, $13.4 \mathrm{~kb}$ wild type and 8 $\mathrm{kb}$ floxed p11) and EcoRI digests (data not shown) distinguished wild-type from floxed alleles.

Deletion of p11 exon 2 from a subpopulation of DRG neurons, but not other cell types, was confirmed at the level of DNA (Fig. 1c), mRNA (Fig. 1d), and protein (Figs. 1e, 2a,b). Using DNA extracted from p11 conditional-null DRG (a mixed population of nociceptive Cre-expressing cells and non-nociceptive and non-neuronal cells not expressing Cre), a smaller band (450 bp) was visible after PCR, representing the deletion of exon 2 from Cre-expressing nociceptive cells. A larger $1.5 \mathrm{~kb}$ band was also visible, representing floxed $\mathrm{p} 11$, but reduced amplification efficiency as compared with the smaller band rendered this very faint. DNA extracted from brain or spinal cord gave the larger $\mathbf{a}$

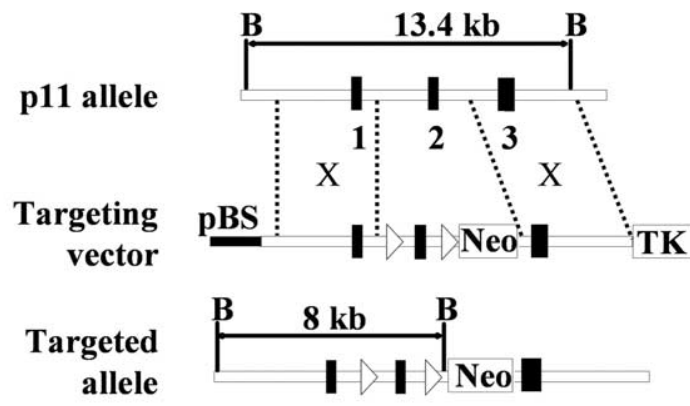

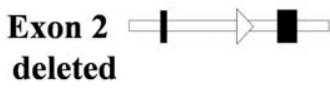
deleted

b

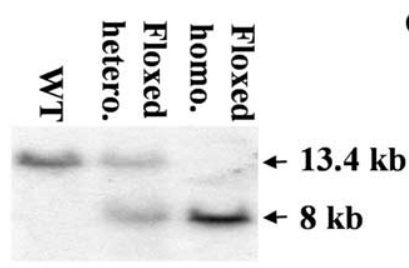

c
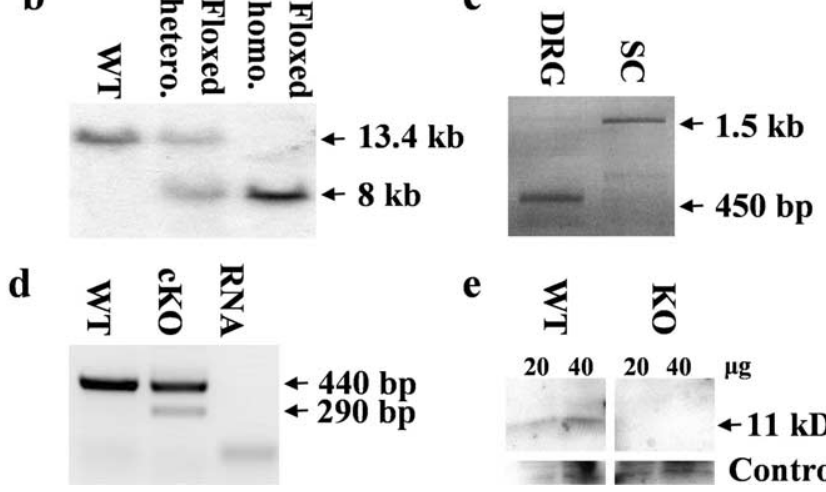

e

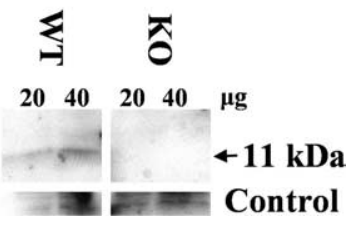

Figure 1. Generation and analysis of 11 floxed mice. $a$, Structure of the targeting construct, wild-type locus, and recombination event. IoxP sites are represented by white arrows. $X$, The sites of homologous recombination; $B, B a m H I$ restriction sites; Neo, a neomycin resistance cassette; TK, the thymidine kinase-negative selection marker. Exons are represented by numbered black blocks. $\boldsymbol{b}$, Southern blot with a BamHl fragment to confirm correct targeting of the p11 locus. Insertion of loxP sites introduces an additional BamHI restriction site and thus a smaller DNA fragment. DNA from wild-type, heterozygous, and homozygous floxed animals is shown. C, PCR showing deletion of $p 11$ exon 2 in DNA from DRG, but not from spinal cord (SC) or brain. $\boldsymbol{d}$, RT-PCR from DRG mRNA, demonstrating deletion of $\mathrm{p} 11$ exon 2 from $\mathrm{p} 11$ conditionalnull (CKO), but not littermate control (WT), DRG. RNA was used as a negative control in the PCR. $\boldsymbol{e}$, Western blot showing deletion of p11 in global-null animals (K0), but not in controls (WT). Protein (40 ng) was taken from total cell lysate. Anti-glyceraldehyde phosphate dehydrogenase was used as a loading control.

band only (1.5 kb). RT-PCR from conditional-null mutant DRG (Fig. 1d) showed a truncated mRNA (290 bp) in addition to the full-length message. mRNA from littermate control floxed p11 DRG showed only a single full-sized band (440 bp).

Complete deletion of p11 from the global-null animal was confirmed using Western blot (Fig. 1e). A band was observed at $11 \mathrm{kDa}$ in control protein isolated from floxed p11 mice, but not in protein extracted from the p11 global-null. Immunocytochemical experiments with overnight cultures of DRG neurons from conditional-null animals were used to examine the extent of p11 deletion in these animals. Figure $2 a$ shows cells from conditional-null mutants and littermate controls stained with anti-p 11 antibody. Greater than $85 \%$ of neurons in control cultures showed an intense staining with a distinctive membrane localization. Fewer than $30 \%$ of neurons from the conditionalnull culture, however, were stained, consistent with p11 deletion. A population of cells from conditional-null DRG cultures retained p11 immunoreactivity, particularly non-neuronal cell types, but including some neuronal cells. These are likely to correspond to cells that do not express $\mathrm{Na}_{\mathrm{V}} 1.8$ nor, as a consequence, 
Cre activity. This assumption was confirmed by costaining with anti- $\mathrm{Na}_{\mathrm{V}} 1.8$. Representative cells are shown in Figure $2 b$. In conditional-null cultures p11 immunoreactivity was absent in all $\mathrm{Na}_{\mathrm{V}} 1.8$ positive cells, whereas all p11-positive cells displayed a lack of $\mathrm{Na}_{\mathrm{V}} 1.8$ immunoreactivity. A small proportion of neuronal cells exhibited neither p11 nor $\mathrm{Na}_{\mathrm{V}} 1.8 \mathrm{immu}$ noreactivity. Because these cells were present in similar proportions in both control and conditional-null cultures, it was concluded that p11 may be absent from or present in low levels in certain cell types. This is supported by in situ hybridization data from previous studies (Okuse et al., 2002). Thus we conclude that the cell type-specific deletion of $\mathrm{p} 11$ is both effective and specific to nociceptors.

\section{p11 deletion does not affect the survival} of DRG neurons

Whole sectioned DRG were examined to test for effects of p11 deletion on neuron survival. Small unmyelinated cells, most of which are nociceptors, were labeled with peripherin whereas larger myelinated cells were labeled with anti-neurofilament antibody N200. Sections from p11 conditionalnull mice DRG had a normal appearance (Fig. 2c), with no significant difference from wild type in the proportions of peripherinor neurofilament-positive cells (Fig. 2c).

Trafficking of $\mathrm{Na}_{\mathrm{V}} 1.8$ in DRG neurons is attenuated by $\mathrm{p} 11$ deletion, but annexin 2 is unaffected

p11 is thought to be involved in the trafficking of annexin 2 to the plasma membrane (Deora et al., 2004). To determine whether any observed phenotypic effects were annexin 2-mediated or attributable solely to p11 absence, we examined the effect of p11 deletion on annexin 2 localization in cultured DRG neurons. Annexin 2 was found to be concentrated at the plasma membrane in both wild-type (floxed) and p11-null cells (Fig. $2 d$ ). We also compared annexin 2 levels in crude plasma membrane preparations, using tissue from global p11null animals. After the isolation of membrane proteins by centrifugation, Western blots revealed broadly similar levels of annexin 2 from floxed p11 and p11-null animals (Fig. 2e1), showing that p11 is not essential for the presence of annexin 2 at the membrane. This is consistent with previous results that used short-interfering RNAmediated depletion of p11 in cultured cells (Zobiack et al., 2003).

The trafficking of $\mathrm{Na}_{\mathrm{V}} 1.8$ by $\mathrm{p} 11$ has been demonstrated in heterologous cell expression systems (Okuse et al., 2002), but not in neurons. Western blots revealed reduced protein levels in global-null DRG membrane preparations (Fig. 2e2). This corresponds with the electrophysiological results observed in p11-null

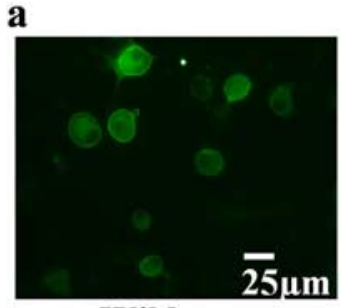

b

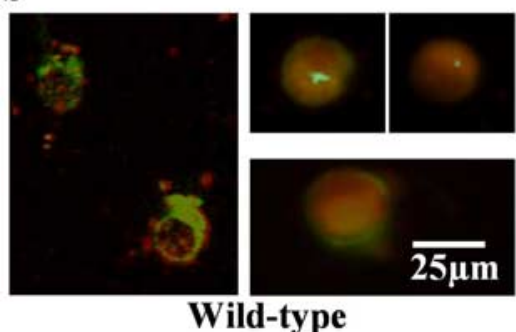

c

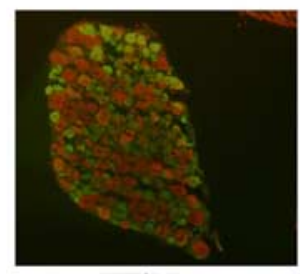

Wild-type

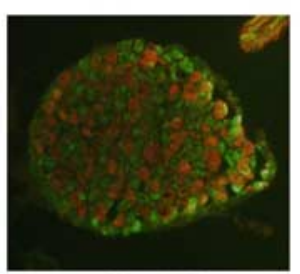

p11 cKO

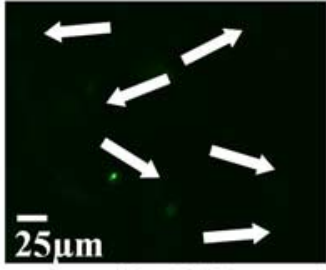

p11 cKO

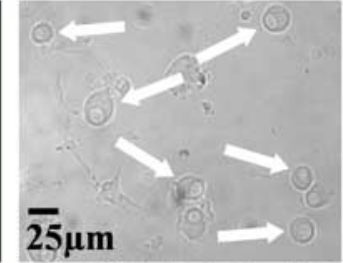

p11 cKO (bright field)

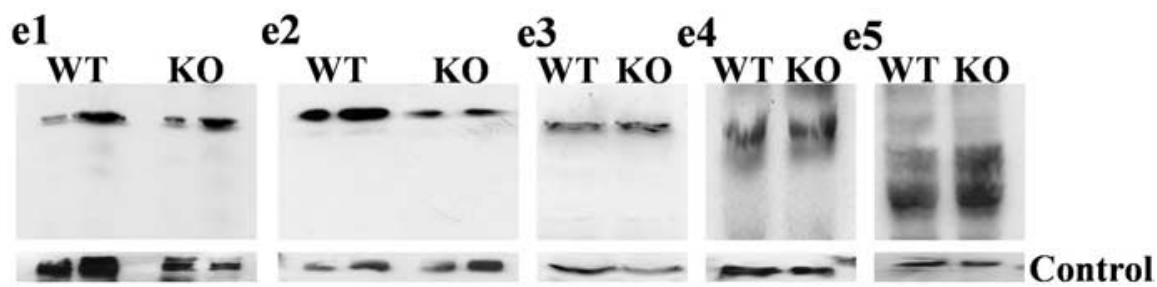

Figure 2. Effects of $p 11$ deletion on cell survival and membrane trafficking of p11-associated proteins. $\boldsymbol{a}$, Acutely cultured DRG neurons from p11 conditional-null (cKO) and littermate control animals (Wild-type) stained with antibody to p11. Locations of unstained cells in the conditional-null are shown by white arrows, replicated on the adjacent bright-field image. $\boldsymbol{b}$, Acutely cultured DRG neurons (as in $\boldsymbol{a}$ ) stained with antibodies to $\mathrm{p} 11$ (green) and $\mathrm{Na}_{\mathrm{v}} 1.8$ (red). Overlap of $\mathrm{p} 11$ and $\mathrm{Na}_{\mathrm{v}} 1.8$ staining can be seen in cells from littermate control; $\mathrm{p} 11$ and $\mathrm{Na}_{\mathrm{y}} 1.8$ expression appears mutually exclusive in cells from the cK0 animals. c, DRG sections from floxed p11 littermate control (Wild-type) and p11 conditional-null mice (cK0) stained with anti-peripherin (green) and N200 (red). No difference in ratio was observed between littermate control $(n=11)$ and p11 conditional-null $(n=24)$ sections. Peripherin control (Peri), $67 \pm 3 \%$; 11 conditional-null, $64 \pm 4 \%$; $\mathrm{N}-200$ control, $37 \pm 3 \%$; 11 conditional-null, $38 \pm$ $4 \%$. Error bars represent mean \pm SEM.d, Acutely cultured DRG neurons (Wild-type, littermate control; cK0, p11 conditional-null) stained with anti-annexin 2. Membrane localization is evident but appears to be unaffected by $p 11$ deletion. $\boldsymbol{e}$, Western blots performed on crude DRG plasma membrane preparations from global p11-null (KO) and control (WT) animals, using anti-annexin 2 (e1). No differences were evident (WT 20, $40 \mu \mathrm{g} ; \mathrm{KO} 20,40 \mu \mathrm{g}$ ). e2, Anti-Na 1.8 , using crude plasma membrane preparations. A reduction in membrane levels was observed (WT 20, $40 \mu \mathrm{g} ; \mathrm{K} 0$ 20, $40 \mu \mathrm{g}$ ). e3, Anti-Na 1.8 , using total cell lysate. No differences were observed (WT and K0, $400 \mu \mathrm{g}$ ). e4, Anti-5- $\mathrm{HT}_{1 \mathrm{~B}}$. No differences in membrane levels were observed (WT and KO, $40 \mu \mathrm{g}$ ). e5, Anti-ASIC1. No differences in membrane levels were observed (WT and K0, $40 \mu \mathrm{g}$ ).

neurons (see below). To confirm that this difference was attributable to trafficking and not to changes in expression levels of $\mathrm{Na}_{\mathrm{V}} 1.8$, we performed Western blots using total DRG cell lysate (Fig. 2e3). No difference was observed between control and p11-null lysate.

Global-null membrane levels of $5-\mathrm{HT}_{1 \mathrm{~B}}$ (Fig. 2e4) did not appear to be altered substantially by p11 deletion despite the recent evidence of $\mathrm{p} 11-5-\mathrm{HT}_{1 \mathrm{~B}}$ colocalization at the plasma membrane (Svenningsson et al., 2006). 
ASIC1 membrane levels also appeared to be unchanged by p11 deletion (Fig. 2e5), as assessed by Western blotting, which also may be attributable to inclusion of the protein in other membrane-bound compartments.

p11 conditional-null mutants show electrophysiological deficits in DRG neurons and in WDR neurons in the spinal cord

DRG neurons

Voltage-gated sodium currents were recorded from p11-null and floxed p11 DRG neurons of $<25 \mu \mathrm{m}$ diameter (Cre-expressing nociceptors). Cultures from both populations were viable and showed a similar cell size distribution between genotypes (littermate control mean diameter, $22.6 \pm 0.7 \mu \mathrm{m}$; p11 conditionalnull, $21.8 \pm 0.7 \mu \mathrm{m} ; n=180$ of each). Currents appeared similar in both groups, as shown in example traces (Fig. 3a2). TTXresistant currents were examined and found to demonstrate comparable current-voltage relationships in both p11-null and control floxed p11 neurons (Fig. 3a3). Results for both TTXresistant and TTX-sensitive currents in floxed p11 neurons corresponded well with those obtained from wild-type mice (C57BL/6) (Nassar et al., 2004).

Deletion of $\mathrm{p} 11$ had a significant effect on TTX-resistant current density, which was reduced by approximately $50 \%$ in the p11-null as compared with floxed p11 DRG neurons (Fig. 3a1), indicating a significant reduction in the number of functional channels per unit membrane area.

TTX-sensitive current densities were not significantly different between p11-null and floxed p11 neurons. A slight increase in mean current density in p11-null cells (Fig. 3a1) may reflect some form of compensatory expression resulting from the reduction in $\mathrm{Na}_{\mathrm{V}} 1.8$ trafficking.

\section{Spinal cord}

Recordings were made from a total of 22 WDR neurons in $\mathrm{p} 11$ conditional-null $(n=11)$ and littermate control floxed p11 $(n=$ 11) mice. The mean depths from the surface of the spinal cord of the neurons were $471 \pm 30$ and $508 \pm 39 \mu \mathrm{m}$, respectively, corresponding to the deep laminae.

Neuronal responses evoked by noxious stimuli were altered in mice lacking p11 as compared with littermate controls. p11 conditional-null mice showed marked deficits in mechanical and thermal coding when compared with controls (Fig. $3 b-d$ ), which were found to be statistically significant for the total evoked neuronal activity (Fig. 3b2,c2) $(p<0.05)$. p11 conditional-null mice also showed a statistically significant reduction in their dorsal horn neuronal activity to noxious pinch stimulus $(p<0.05)$, yet not to noxious cold or brush stimuli (Fig. $3 d$ ).

In contrast, the evoked responses to transcutaneous electrical stimulation of the peripheral receptive field showed no difference between groups either in the threshold for the activation of A-fiber and C-fiber afferents or in their evoked neuronal responses and related postdischarge, input, and wind-up measurements. The occurrence and rate of ongoing spontaneous firing were similar in both groups (data not shown).

\section{p11 conditional-null mice show no gross abnormalities}

p11 conditional-null mice were healthy, fertile, and apparently normal. They showed no overt differences from floxed p11 littermates in appearance and spontaneous behavior. Weight (ageand sex-matched) and motor coordination were observed to be comparable between floxed p11 and p11 conditional-null animals (data not shown).
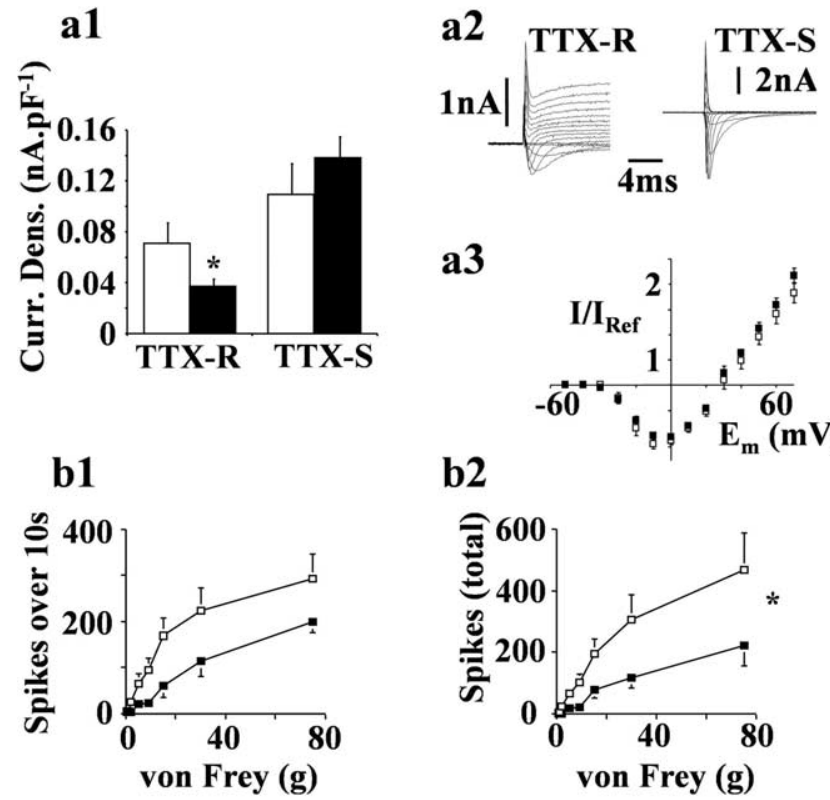

a3

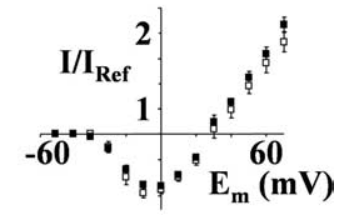

b2

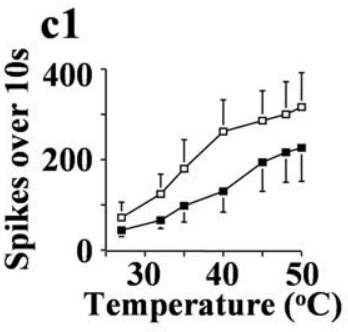

c2

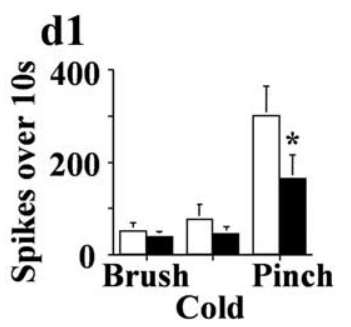

d2

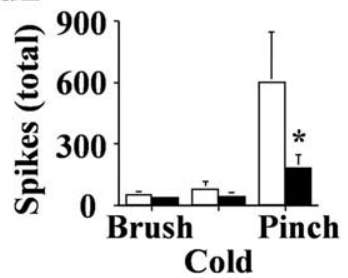

Figure 3. Electrophysiology of p11-null mice. $\boldsymbol{a}$, Whole-cell voltage clamp of DRG neurons. $\boldsymbol{a 1}$, TTX-sensitive (TTX-S) and TTX-resistant (TTX-R) peak sodium current densities in floxed p11 (white; $n=24$ ) and p11-null (black; $n=42$ ) mice. A significant decrease in TTX-Rsodium current density was observed in the p11-null mice. p11-null, $0.037 \pm 0.0056 \mathrm{nA} / \mathrm{pF}$ and $n=42$; floxed p11, $0.071 \pm$ $0.016 \mathrm{nA} / \mathrm{pF}$ and $n=26$ ( $p=0.016$; Mann-Whitney Rank Sum test). No significant difference was observed in TTX-S current density. p11-null, $0.14 \pm 0.017 \mathrm{nA} / \mathrm{pF}$ and $n=42$; floxed p11, $0.11 \pm$ $0.024 \mathrm{nA} / \mathrm{pF}$ and $n=22(p=0.19) . a 2$, Example TTX-Rand TTX-Scurrent traces from representative neurons. a3, Current-voltage relationship for TTX-R currents from p11-null (black boxes; $n=7$ ) and littermate control (white boxes; $n=7$ ) neurons. No difference was observed. $\boldsymbol{b}$, p11 conditional-null mice (black boxes) display marked deficits in mechanically evoked dorsal horn neuronal activity compared with littermate controls (white boxes). WDR neurons recorded from p11-null mice $(n=11)$ show significantly reduced activity $(p<0.05)$ to punctate mechanical von Frey stimuli. Data are shown during stimulus application (b1) and for total evoked activity to the stimulus (b2) compared with littermate control mice $(n=11)$. c, The same neurons show significantly reduced response $(p<0.05)$ to thermal stimuli (water jet). Data are shown during stimulus application ( $\mathbf{c}$ ) and for total evoked activity to the stimulus (c2).d, These neurons also show significantly reduced activity to noxious pinch stimuli $(p<0.05)$, but not to brush or noxious cold $\left(1^{\circ} \mathrm{C}\right)$ when compared with controls for the duration of the stimuli (d1) and for total evoked activity to the stimulus (d2). Stimuli were applied for 10 s to the peripheral receptive field of the neuron on the hindpaw. Data are expressed as mean \pm SEM; ${ }^{*} p<0.05$.

p11 conditional-null mice show deficits in noxious mechanosensation

The threshold of paw withdrawal in response to von Frey hairs did not differ between 11 conditional-null and floxed p11 litter- 


\section{a}

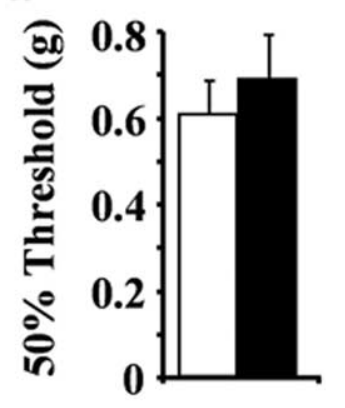

c

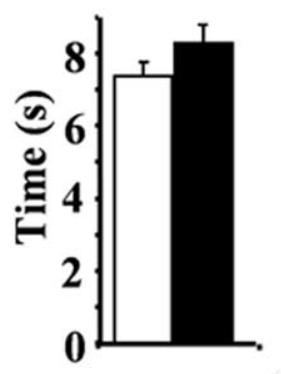

b

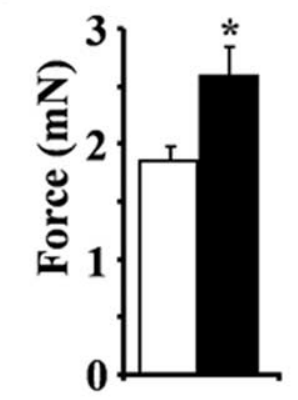

d

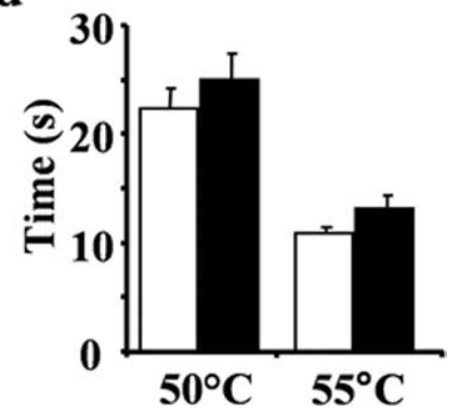

Figure 4. Acute pain behavior in p11 conditional-null and control (floxed p11) mice. $\boldsymbol{a}$, Response to mechanical stimulation using von Frey hairs was not significantly different between littermate control floxed p11 (white; $n=5 ; 0.059 \pm 0.008 \mathrm{~g}$ ) and p11 conditional-null (black; $n=7 ; 0.067 \pm 0.010 \mathrm{~g}$ ) mice. $\boldsymbol{b}, \mathrm{p} 11$ conditional-null mice (black; $n=13$ ) showed partial analgesia to noxious mechanical pressure applied to the tail using the Randall-Selitto apparatus compared with littermate controls (white; $n=13$ ) ( $p 11$ conditional-null, $0.0019 \pm$ $0.00012 \mathrm{~N}$ and $n=13$; floxed $\mathrm{p} 11$ littermate control, $0.0026 \pm 0.00025 \mathrm{~N}$ and $n=13)(p=$ 0.013; Student's $t$ test). c, Noxious thermal stimulation using Hargreaves' apparatus. No significant difference in latency of hindpaw withdrawal was observed between littermate control (white; $n=11 ; 7.41 \pm 0.35 \mathrm{~s}$ ) and p11 conditional-null (black; $n=12 ; 8.28 \pm 0.50 \mathrm{~s}$ ) mice. $\boldsymbol{d}$, Response to noxious thermal stimulation using the hotplate apparatus was not significantly different between littermate control (white; $n=14$ ) and $p 11$ conditional-null (black; $n=15$ ) mice. At $50^{\circ} \mathrm{C}$, littermate control, $22.4 \pm 1.9 \mathrm{~s}$; conditional-null, $25.1 \pm 2.4 \mathrm{~s}(p=0.38$; Student's $t$ test). At $55^{\circ} \mathrm{C}$, littermate control, $10.9 \pm 0.6 \mathrm{~s}$; conditional-null, $13.1 \pm 1.3 \mathrm{~s}$ ( $p=$ 0.12 ; Student's $t$ test). All results are shown as mean $\pm \mathrm{SEM} ;{ }^{*} p<0.05$.

mate control animals (Fig. 4a). A significant increase in pain threshold with the Randall-Selitto apparatus, however, was observed in the p11 conditional-null mutant (Fig. 4b), showing partial analgesia to noxious mechanical stimuli applied to the tail. These results are consistent with the deficits observed in $\mathrm{Na}_{\mathrm{V}} 1.8$ knock-out mice (Akopian et al., 1999).

Paw withdrawal in response to noxious radiant heat (Hargreaves' apparatus) was not altered significantly in the p11 conditional-null mutant (Fig. $4 c$ ). There were no significant differences in hotplate latency at 50 or $55^{\circ} \mathrm{C}$ (Fig. $4 d$ ). For all thermal tests, however, p11 conditional-null mice showed a slightly increased latency of response, suggesting that despite a lack of significance in any individual test there may be a slight thermal analgesia associated with the deletion of p11, similar to that observed in the $\mathrm{Na}_{\mathrm{V}} 1.8$ knock-out mouse (Akopian et al., 1999).

p11 conditional-null mice show deficits in neuropathic, but not inflammatory, pain

The involvement of $\mathrm{p} 11$ in inflammatory pain was investigated by using the carrageenan, NGF, and formalin models. After injection of carrageenan, profound thermal hyperalgesia was observed

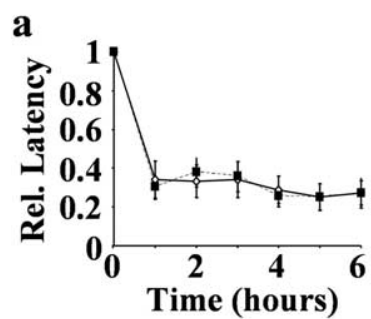

b
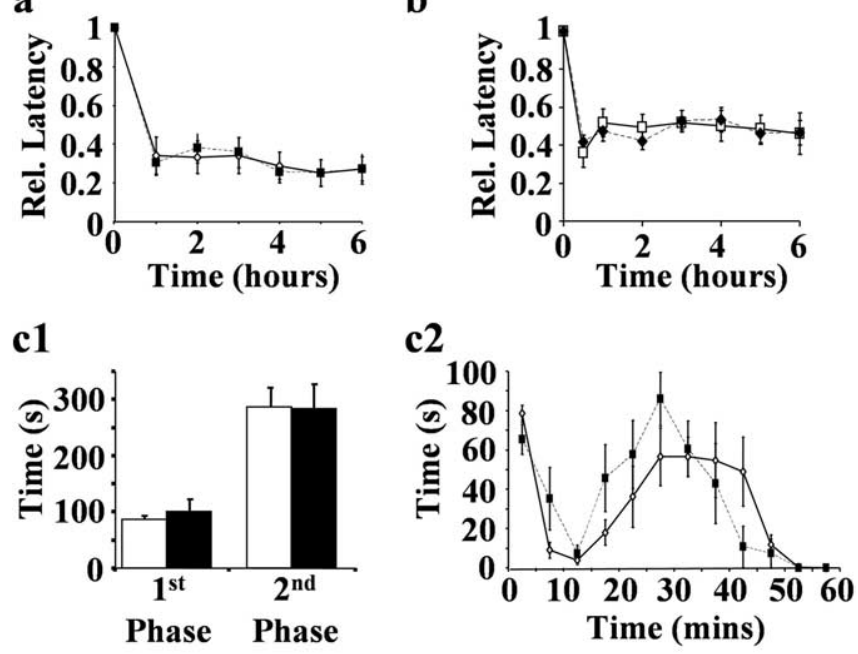

d

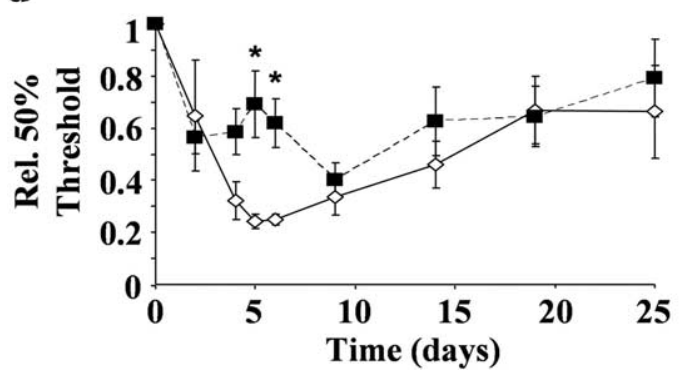

Figure 5. Inflammatory and neuropathic pain behavior in p11 conditional-null mice. $\boldsymbol{a}$, Thermal hyperalgesia, tested using Hargreaves' apparatus, after intraplantar injection of $2 \%$ carrageenan $(20 \mu l)$. Both floxed p11 littermate control (white; $n=6$ ) and p11 conditionalnull (black; $n=6$ ) mice developed pronounced hyperalgesia, with no significant difference between genotypes. $\boldsymbol{b}$, NGF-induced hyperalgesia. Both littermate control (white; $n=5$ ) and p11 conditional-null (black; $n=7$ ) mice developed profound thermal hyperalgesia. $c 1$, Pain behavior after intraplantar injection of $20 \mu \mathrm{l}$ of $5 \%$ formalin. Time spent licking/biting the injected hindpaw was recorded in 5 min sections. No significant reduction in time of pain behavior was seen at Phase $1(0-10 \mathrm{~min})$ or at Phase $2(10-55 \mathrm{~min})$ between littermate control (white; $n=7$ ) and $p 11$ conditional-null (black; $n=5$ ) mice. Phase 1 littermate control, $87.4 \pm$ $5.3 \mathrm{~s}$; conditional-null, $100.6 \pm 22.2 \mathrm{~s}$. Phase 2 littermate control, $286.8 \pm 33.9$ s; conditionalnull, $283.2 \pm 43.2$ s. c2, Time course of the formalin test. A characteristic biphasic response was observed. $\boldsymbol{d}$, Mechanical allodynia, measured by using von Frey hairs, resulting from the Chung model of neuropathic pain. A significant reduction in mechanical allodynia ( $p=0.031$; twoway repeated measures ANOVA) was observed overall in the 11 conditional-null (black; $n=7$ ) when compared with the littermate control (white; $n=5$ ) mice. Data are expressed as mean \pm SEM; ${ }^{*} p<0.05$ (individual points).

from $1 \mathrm{~h}$. No difference was observed between floxed $\mathrm{p} 11$ and $\mathrm{p} 11$ conditional-null mice in either time course or maximal levels of hyperalgesia (Fig. 5a). Injection of NGF produced a similar result (Fig. 5b), showing no difference between p11 conditional-null and floxed p11 mice. The formalin model is believed to represent chronic pain, including a centrally driven component. Injection of formalin produced a characteristic biphasic response in both floxed p11 and p11 conditional-null mice. The pain behavior in each phase was not significantly different between genotypes (Fig. $5 c 1, c 2$ ), again consistent with the findings in $\mathrm{Na}_{\mathrm{V}} 1.8$-null mice (Nassar et al., 2005).

Deletion of p11 from nociceptors substantially reduced the mechanical allodynia associated with L5 spinal nerve injury, a model of neuropathic pain (Fig. $5 d$ ). Floxed p11 animals showed a substantial decrease in response threshold, to $\sim 25 \%$ of baseline by day 5 . In contrast, p11 conditional-null mice maintained a 
threshold of $\sim 60 \%$ of baseline, significantly different from control animals ( $p=0.031$; two-way repeated measures ANOVA).

\section{Discussion}

The $\mathrm{S} 100$ protein $\mathrm{p} 11$ is broadly expressed in a range of tissues and has been implicated in many cellular processes, such as fibrinolysis (Kwon et al., 2002), meaning that a global-null mutant animal would therefore be expected to display a complex phenotype, precluding a definitive analysis of its role in pain behavior. In particular, recently described effects on depression-related behavior (Svenningsson et al., 2006) would be likely to confound the interpretation of nociceptive behavioral phenotypes. We therefore created a conditional (tissue-specific) null mutant to examine the effect of deleting p11 only from nociceptive sensory neurons.

In this study we found that there is indeed a role for $\mathrm{p} 11$ in nociceptive pathways of the peripheral nervous system. Effects of p11 deletion on the electrophysiological properties of primary nociceptors are translated into deficits in noxious coding at the dorsal horn and into altered pain behavior. The functional expression of the voltage-gated sodium channel $\mathrm{Na}_{\mathrm{V}} 1.8$ is reduced, but not abolished, in the absence of p11. Altered pain behavior is similar to that observed in the Nav1.8 knock-out, but there are substantial differences in the inflammatory and neuropathic pain phenotypes. Although trafficking of $\mathrm{Na}_{\mathrm{V}} 1.8$ is affected by $\mathrm{p} 11$ deletion, the plasma membrane levels of annexin 2 heavy-chain, which associates with p11, appear to be unaffected. Finally, we have created a valuable tool for the tissue-specific in vivo investigation of p11 function.

\section{p11 conditional-null mutants show reduced TTX-resistant sodium current density and altered coding for thermal and mechanical stimuli}

Deletion of p11 from DRG neurons was found to reduce the responsiveness of damage-sensing nerves both at the periphery and at the level of the dorsal horn. TTX-resistant sodium current densities attributed to $\mathrm{Na}_{\mathrm{V}} 1.8$ in small DRG neurons were found to be reduced significantly in the absence of $\mathrm{p} 11$, as predicted by the work of Okuse et al. (2002). Because $\mathrm{Na}_{\mathrm{V}} 1.8$ has been shown to have a specialized function in pain pathways (Akopian et al., 1999) and action potential electrogenesis (Renganathan et al., 2001), its regulation by $\mathrm{p} 11$ provides a potential mechanism for the control of nociceptive thresholds. Primary cultured neurons may underestimate the effect of p11 deletion as potential p11induced channel clustering at nerve termini may be overlooked (Kretschmer et al., 2002). The functional expression of $\mathrm{Na}_{\mathrm{V}} 1.8$ was not abolished completely by the absence of p11, implying that factors other than p11 are capable of trafficking this channel to the plasma membrane. These may include candidates identified by yeast two-hybrid screening, such as Papin (Malik-Hall et al., 2003). Alternatively, $\mathrm{p} 11$ homologs may bind to $\mathrm{Na}_{\mathrm{V}} 1.8$ in the presence of increased local $\mathrm{Ca}^{2+}$ concentrations. The S100 protein S100A11 shares the putative $\mathrm{Na}_{\mathrm{V}} 1.8$ binding site of $\mathrm{p} 11$ and may also be capable of $\mathrm{Na}_{\mathrm{V}} 1.8$ trafficking (Poon et al., 2004).

Reduction in functional sodium channel expression appears to be specific to $\mathrm{Na}_{\mathrm{V}} 1.8$, because TTX-sensitive currents were not reduced by deletion of $\mathrm{p} 11$.

The physiological significance of these results was examined by recording electrical activity from the dorsal horn. p11-null C-fibers showed reduced coding for mechanical and thermal stimuli at the level of the dorsal horn, particularly in the noxious range. An absence of poststimulus discharge was also noted. Effects on more than one stimulus modality mean that this reduced coding is unlikely to be attributable to an interaction of p11 with a single modality-specific transducer. No difference was observed using transcutaneous electrical stimulation along the sciatic nerve, implying that the reduction in coding is mediated by events at the nerve terminal rather than by a general reduction in peripheral neuron excitability. This is consistent with the proposed role of $\mathrm{Na}_{\mathrm{V}} 1.8$ in setting thresholds of depolarization at the nerve terminal (Akopian et al., 1999).

The effect on coding at the dorsal horn is not necessarily mediated by $\mathrm{Na}_{\mathrm{V}} 1.8$, however. It remains possible that a proportion of the reduced coding observed resulted from altered trafficking of other proteins in the peripheral nervous system. We did not see deficits in trafficking of ASICla or $5-\mathrm{HT}_{1 \mathrm{~B}}$, but this may be attributable to their inclusion in other membrane-bound compartments, causing the presence of these proteins in membrane preparations.

\section{Pain behavior is affected by deletion of $\mathrm{p} 11$ from nociceptors}

As predicted by our in vitro results, we observed deficits in pain behavior in p11 conditional-null mutants. Acute pain models revealed a phenotype similar to that of the $\mathrm{Na}_{\mathrm{V}} 1.8$-null mutant, in which the largest effect was seen in the Randall-Selitto test (Akopian et al., 1999). The magnitude of analgesia in the absence of p11 was $\sim 50 \%$ of that seen in the $\mathrm{Na}_{\mathrm{V}} 1.8$-null mutant, correlating with the $50 \%$ reduction in TTX-resistant $\mathrm{Na}^{+}$currents observed here. This suggests that the mechanical analgesia observed in the p11-null mouse is mediated by reduced trafficking of $\mathrm{Na}_{\mathrm{V}} 1.8$ to the plasma membrane.

p11 is regulated by a variety of factors including the proinflammatory NGF (Masiakowski and Shooter, 1988) and interferon- $\gamma$ (Huang et al., 2003), suggesting a possible role in pain processes. Additionally, NGF-induced hyperalgesia has been shown to be strongly dependent on the presence of $\mathrm{Na}_{\mathrm{V}} 1.8$ (Kerr et al., 2001). Surprisingly, no differences in inflammatory pain were observed between $\mathrm{p} 11$ conditional-null and floxed $\mathrm{p} 11$ littermate control animals. These data suggest that the increase in functional expression of $\mathrm{Na}_{\mathrm{V}} 1.8$ by NGF appears to be p11-independent.

\section{Nociceptor-specific p11 deletion reduces neuropathic pain behavior}

A marked reduction in neuropathic pain was observed in the p11 conditional-null mouse, despite the fact that p11 mRNA was not found to be upregulated in an orofacial neuropathic pain model (Eriksson et al., 2005). Our results illustrate the contribution of p11-containing primary nociceptors to the generation of neuropathic pain. The downstream effector or effectors through which p11 influences such behavior have yet to be identified. Initial candidates include proteins known to bind to p11, such as $\mathrm{Na}_{\mathrm{V}} 1.8$, ASIC1a, TASK-1, TRPV5/6, or 5-HT 1 B, although it remains possible that other proteins also bind $\mathrm{p} 11$. Deletion of $\mathrm{Na}_{\mathrm{V}} 1.8$ did not block the development of experimentally induced neuropathic pain (Kerr et al., 2001), implying that p11 may act via another mechanism in this model, but it did prevent spontaneous activity in damaged sensory axons (Roza et al., 2003) and reduced late-phase ectopic discharge in neuroma C-fibers (Okuse et al., 1997). The roles of TASK-1 and 5- $\mathrm{HT}_{1 \mathrm{~B}}$ in neuropathic pain have not been examined. The contribution of the TASK channels to the resting membrane potential makes TASK-1 potentially important in altering neuronal excitability. Conflicting data on the effect of p11 on TASK-1 trafficking, however, make the probable effect of $\mathrm{p} 11$ deletion on $\mathrm{K}^{+}$currents unclear (Girard et al., 2002; Renigunta et al., 2006). ASICla has 
been shown to be downregulated in several models of neuropathic pain (Poirot et al., 2006), with corresponding reduced functional expression. Poirot et al. (2006) suggest an inhibitory contribution of ASIC1a-related currents in neuropathic pain, inconsistent with a role for ASIC1a in p11-enhanced neuropathic pain behavior. There are no data on the presence or possible role of TRPV5/6 in DRG neurons.

A mechanism for the alteration of neuropathic pain behavior by $\mathrm{p} 11$ in sensory neurons is thus lacking. It is remarkable that this 100-amino-acid peptide is involved in the trafficking of such a diverse range of ion channels and receptors through direct interactions. Whether other p11-like molecules at high calcium concentrations with activated $\mathrm{EF}$ hands can mimic these trafficking effects is unknown. p11 has been proposed to organize microdomains in the cell membrane through the formation of cholesterol-stabilized phosphatidylinositol 4,5-bisphosphate clusters. It is possible that these lipid domains within the neuronal membrane organize channel distribution to affect neuronal excitability and that not only trafficking to the membrane but subsequent membrane localizations are determined by interactions with p11 (Gokhale et al., 2005).

\section{Tissue-specific investigation of p11 function}

Many functions have been proposed for $\mathrm{p} 11$ in a wide range of tissue types. For example, the discovery of the central role of annexin 2 in angiogenesis and fibrin homeostasis (Ling et al., 2004), together with the observation that the C-terminal lysines of p11 bind tPA and plasminogen, resulting in the stimulation of tPA-dependent plasmin production (for review, see Kwon et al., 2005), suggests that 11 may be an important regulator of angiogenesis and fibrin homeostasis. These processes are essential for phenomena such as cancer invasion and metastasis, and neonatal hyperoxia-induced retinopathy. The effect of $\mathrm{p} 11$ deletion in vivo has been investigated only with respect to the $\mathrm{p} 11-5-\mathrm{HT}_{1 \mathrm{~B}}$ receptor interaction in depression (Svenningsson et al., 2006) using global-null mutants. By crossing the floxed p11 mouse with animals expressing Cre under the control of a tissue-specific promoter, we can produce conditional-null mutants for a wide range of tissues. This is a powerful tool, allowing tissue-specific discrimination of the many functions of $\mathrm{p} 11$.

We have demonstrated for the first time the importance of the S100 protein p11 in nociceptive pathways in primary sensory neurons. Although the diverse functions of p11 mean that it is unlikely to be a good therapeutic target for neuropathic pain, disruption of specific p11-channel/receptor interactions may lead to novel therapeutic interventions for a range of clinically important conditions.

\section{References}

Akopian AN, Sivilotti L, Wood JN (1996) A tetrodotoxin-resistant voltagegated sodium channel expressed by sensory neurons. Nature 379:257-262.

Akopian AN, Souslova V, England S, Okuse K, Ogata N, Ure J, Smith A, Kerr BJ, McMahon SB, Boyce S, Hill R, Stanfa LC, Dickenson AH, Wood JN (1999) The tetrodotoxin-resistant sodium channel SNS has a specialized function in pain pathways. Nat Neurosci 2:541-548.

Deora AB, Kreitzer G, Jacovina AT, Hajjar KA (2004) An annexin 2 phosphorylation switch mediates p11-dependent translocation of annexin 2 to the cell surface. J Biol Chem 279:43411-43418.

Djouhri L, Fang X, Okuse K, Wood JN, Berry CM, Lawson SN (2003) The TTX-resistant sodium channel $\mathrm{Na}_{\mathrm{V}} 1.8$ (SNS/PN3): expression and correlation with membrane properties in rat nociceptive primary afferent neurons. J Physiol (Lond) 550:739-752.

Donier E, Rugiero F, Okuse K, Wood JN (2005) Annexin II light chain p11 promotes functional expression of acid-sensing ion channel ASICla. J Biol Chem 280:38666-38672.

Duprat F, Lesage F, Fink M, Reyes R, Heurteaux C, Lazdunski M (1997) TASK, a human background $\mathrm{K}^{+}$channel to sense external $\mathrm{pH}$ variations near physiological pH. EMBO J 16:5464-5471.

Eriksson J, Jablonski A, Persson AK, Hao JX, Kouya PF, Wiesenfeld-Hallin Z, Xu XJ, Fried K (2005) Behavioral changes and trigeminal ganglion sodium channel regulation in an orofacial neuropathic pain model. Pain 119:82-94.

Farley FW, Soriano P, Steffen LS, Dymecki SM (2000) Widespread recombinase expression using FLPeR (flipper) mice. Genesis 28:106-110.

Gerke V, Moss SE (2002) Annexins: from structure to function. Physiol Rev $82: 331-371$.

Girard C, Tinel N, Terrenoire C, Romey G, Lazdunski M, Borsotto M (2002) p11, an annexin II subunit, an auxiliary protein associated with the background $\mathrm{K}^{+}$channel, TASK-1. EMBO J 21:4439-4448.

Gokhale NA, Abraham A, Digman MA, Gratton E, Cho W (2005) Phosphoinositide specificity of and mechanism of lipid domain formation by annexin A2-p11 heterotetramer. J Biol Chem 280:42831-42840.

Huang XL, Pawliczak R, Yao XL, Cowan MJ, Gladwin MT, Walter MJ, Holtzman MJ, Madara P, Logun C, Shelhamer JH (2003) Interferon- $\gamma$ induces p11 gene and protein expression in human epithelial cells through interferon- $\gamma$-activated sequences in the p11 promoter. J Biol Chem 278:9298-9308.

Kerr BJ, Souslova V, McMahon SB, Wood JN (2001) A role for the TTXresistant sodium channel $\mathrm{Na}_{\mathrm{V}} 1.8$ in NGF-induced hyperalgesia, but not neuropathic pain. NeuroReport 12:3077-3080.

Kretschmer T, Happel LT, England JD, Nguyen DH, Tiel RL, Beuerman RW, Kline DG (2002) Accumulation of PN1 and PN3 sodium channels in painful human neuroma- evidence from immunocytochemistry. Acta Neurochir (Wien) 144:803-810.

Kwon M, Caplan JF, Filipenko NR, Choi KS, Fitzpatrick SL, Zhang L, Waisman DM (2002) Identification of annexin II heterotetramer as a plasmin reductase. J Biol Chem 277:10903-10911.

Kwon M, Macleod TJ, Zhang Y, Waisman DM (2005) S100A10, annexin A2, and annexin a2 heterotetramer as candidate plasminogen receptors. Front Biosci 10:300-325.

Ling Q, Jacovina AT, Deora A, Febbraio M, Simantov R, Silverstein RL, Hempstead B, Mark WH, Hajjar KA (2004) Annexin II regulates fibrin homeostasis and neoangiogenesis in vivo. J Clin Invest 113:38-48.

Malik-Hall M, Poon W-YL, Baker MD, Wood JN, Okuse K (2003) Sensory neuron proteins interact with the intracellular domains of sodium channel $\mathrm{Na}_{\mathrm{V}}$ 1.8. Mol Brain Res 110:298-304.

Masiakowski P, Shooter EM (1988) Nerve growth factor induces the genes for two proteins related to a family of calcium-binding proteins in PC12 cells. Proc Natl Acad Sci USA 85:1277-1281.

Matthews EA, Wood JN, Dickenson AH (2006) $\mathrm{Na}_{\mathrm{V}}$ 1.8-null mice show stimulus-dependent deficits in spinal neuronal activity. Mol Pain 2:5.

Nassar MA, Stirling LC, Forlani G, Baker MD, Matthews EA, Dickenson AH, Wood JN (2004) Nociceptor-specific gene deletion reveals a major role for $\mathrm{Na}_{\mathrm{V}} 1.7$ (PN1) in acute and inflammatory pain. Proc Natl Acad Sci USA 101:12706-12711.

Nassar MA, Levato A, Stirling LC, Wood JN (2005) Neuropathic pain develops normally in mice lacking both $\mathrm{Na}_{\mathrm{V}} 1.7$ and $\mathrm{Na}_{\mathrm{V}} 1.8$. Mol Pain 1:24.

Nicholson R, Small J, Dixon AK, Spanswick D, Lee K (2003) Serotonin receptor mRNA expression in rat dorsal root ganglion neurons. Neurosci Lett 337:119-122.

Okuse K, Chaplan SR, McMahon SB, Luo ZD, Calcutt NA, Scott BP, Akopian AN, Wood JN (1997) Regulation of expression of the sensory neuronspecific sodium channel SNS in inflammatory and neuropathic pain. Mol Cell Neurosci 10:196-207.

Okuse K, Malik-Hall M, Baker MD, Poon WY, Kong H, Chao MV, Wood JN (2002) Annexin II light chain regulates sensory neuron-specific sodium channel expression. Nature 417:653-656.

Pawliczak R, Cowan MJ, Huang X, Nanavaty UB, Alsaaty S, Logun C, Shelhamer JH (2001) p11 expression in human bronchial epithelial cells is increased by nitric oxide in a cGMP-dependent pathway involving protein kinase G activation. J Biol Chem 276:44613-44621.

Poirot O, Berta T, Decosterd I, Kellenberger S (2006) Distinct ASIC currents are expressed in rat putative nociceptors and are modulated by nerve injury. J Physiol, in press.

Poon WY, Malik-Hall M, Wood JN, Okuse K (2004) Identification of bind- 
ing domains in the sodium channel $\mathrm{Na}_{\mathrm{V}} 1.8$ intracellular $\mathrm{N}$-terminal region and annexin II light chain p11. FEBS Lett 558:114-118.

Renganathan M, Cummins TR, Waxman SG (2001) Contribution of $\mathrm{Na}_{\mathrm{V}} 1.8$ sodium channels to action potential electrogenesis in DRG neurons. J Neurophysiol 86:629-640.

Renigunta V, Yuan H, Zuzarte M, Rinne S, Koch A, Wischmeyer E, Schlichthorl G, Gao Y, Karschin A, Jacob R, Schwappach B, Daut J, PreisigMuller R (2006) The retention factor p11 confers an endoplasmic reticulum-localization signal to the potassium channel TASK-1. Traffic 7:168-181.

Roza C, Laird JM, Souslova V, Wood JN, Cervero F (2003) The tetrodotoxin-resistant $\mathrm{Na}^{+}$channel $\mathrm{Na}_{\mathrm{V}} 1.8$ is essential for the expression of spontaneous activity in damaged sensory axons of mice. J Physiol (Lond) 550:921-926.

Sambrook J, Fritsch EF, Maniatis T (1989) Molecular cloning: a laboratory manual, 2nd Ed. Cold Spring Harbor, NY: Cold Spring Harbor Laboratory.

Schwenk F, Baron U, Rajewsky K (1995) A Cre-transgenic mouse strain for the ubiquitous deletion of loxP-flanked gene segments including deletion in germ cells. Nucleic Acids Res 23:5080-5081.

Smith PK, Krohn RI, Hermanson GT, Mallia AK, Gartner FH, Provenzano MD, Fujimoto EK, Goeke NM, Olson BJ, Klenk DC (1985) Measurement of protein using bicinchoninic acid. Anal Biochem 150:76-85.

Stirling LC, Forlani G, Baker MD, Wood JN, Matthews EA, Dickenson AH, Nassar MA (2005) Nociceptor-specific gene deletion using heterozygous $\mathrm{Na}_{\mathrm{V}} 1.8$-Cre recombinase mice. Pain 113:27-36.
Svenningsson P, Chergui K, Rachleff I, Flajolet M, Zhang X, El Yacoubi M, Vaugeois JM, Nomikos GG, Greengard P (2006) Alterations in $5-\mathrm{HT}_{1 \mathrm{~B}}$ receptor function by $\mathrm{p} 11$ in depression-like states. Science 311:77-80.

van de Graaf SF, Hoenderop JG, Gkika D, Lamers D, Prenen J, Rescher U, Gerke V, Staub O, Nilius B, Bindels RJ (2003) Functional expression of the epithelial $\mathrm{Ca}^{2+}$ channels (TRPV5 and TRPV6) requires association of the S100A10-annexin 2 complex. EMBO J 22:1478-1487.

Voilley N, de Weille J, Mamet J, Lazdunski M (2001) Nonsteroid antiinflammatory drugs inhibit both the activity and the inflammationinduced expression of acid-sensing ion channels in nociceptors. J Neurosci 21:8026-8033.

Wemmie JA, Chen J, Askwith CC, Hruska-Hageman AM, Price MP, Nolan BC, Yoder PG, Lamani E, Hoshi T, Freeman Jr JH, Welsh MJ (2002) The acid-activated ion channel ASIC contributes to synaptic plasticity, learning, and memory. Neuron 34:463-477.

Wemmie JA, Askwith CC, Lamani E, Cassell MD, Freeman Jr JH, Welsh MJ (2003) Acid-sensing ion channel 1 is localized in brain regions with high synaptic density and contributes to fear conditioning. J Neurosci 23:5496-5502.

Yermolaieva O, Leonard AS, Schnizler MK, Abboud FM, Welsh MJ (2004) Extracellular acidosis increases neuronal cell calcium by activating acidsensing ion channel 1a. Proc Natl Acad Sci USA 101:6752-6757.

Zobiack N, Rescher U, Ludwig C, Zeuschner D, Gerke V (2003) The annexin 2/S100A10 complex controls the distribution of transferrin receptor-containing recycling endosomes. Mol Biol Cell 14:4896-4908. 